\title{
Thymoquinone: shield and sword against SARS-CoV-2
}

\author{
Andrei P. Sommer ${ }^{1 *}$, Horst-Dieter Försterling ${ }^{2}$, Kurt G. Naber ${ }^{3}$ \\ 1. Faculty of Science, Isra University, Amman, Jordan. \\ 2. Department of Chemistry, Philipps University Marburg, Marburg, Germany. \\ 3. Department of Urology, Technical University of Munich, Munich, Germany.
}

Submitted: May 10, 2020

Accepted: May 16, 2020

Published: May 20, 2020

\section{Graphical Abstract}

\section{Abstract}

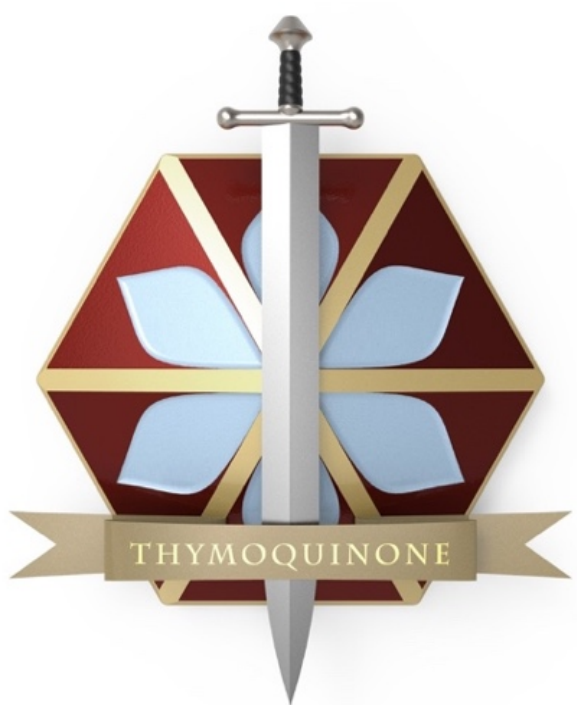

Since its emergence, the epidemic scale of the new coronavirus (SARS-CoV-2) has increased at an extraordinary rate. Governments, medical personnel, researchers, and companies work to the limits of their capabilities, in attempts to combat the virus. Companies are giving up current projects and changing their activities to help with fighting the virus. In this difficult time, every piece of useful information is valuable. Here, we bring to the attention of the scientific and medical community thymoquinone (TQ), a substance mostly unknown to experts in Western countries, which holds the promise to help treat people infected with this novel virus by (1) by inhibiting its proliferation, (2) by killing it, (3) by killing the bacteria associated with pneumonia, (4) with its anti-inflammatory and (5) with its immunomodulatory effect - perhaps acting synergistically, or even as a prophylactic remedy to prevent SARSCoV-2 infection. However, due to its hydrophobicity, the systemic bioavailability of TQ is low. Nanocarriers targeting the lungs exist, and TQ has already been successfully used in nanomedicines targeting different organs except the lungs. Thus, there is not a long way to go. This is the challenge for nanomedicine. It was an anecdotal case report that stimulated the investigation of the therapeutic effect of TQ and the derivation of a mechanism for its dual antiviral action, applicable to COVID-19. Furthermore, by exploiting the material published on the antiviral effect of TQ, we compared its antiviral mechanism with that of chloroquine (CQ) and hydroxychloroquine (HCQ). Our analysis indicates that the antiviral action of TQ is similar and most likely superior to that of CQ and HCQ, however, apparently without the adverse effects reported for CQ and HCQ. The broad antiviral spectrum and the mechanism by which TQ presumably neutralizes the new virus justifies the hypothesis that TQ is effective in treating COVID-19.

*Correspondence: Dr. Andrei P. Sommer, email: andrei.sommer@alumni.uni-ulm.de 


\section{Keywords:}

Coronavirus, SARS-CoV-2, COVID-19, thymoquinone, chloroquine, hydroxychloroquine

\section{Purpose and Rationale}

The purpose of this report is to bring to the attention of the nanomedicine community the antiviral, antibacterial, anti-inflammatory and immunomodulatory potential of the compound thymoquinone (TQ), a substance that occurs in nature dissolved in the volatile fraction of black cumin oil, which has already been suggested for the treatment of COVID-19, and to stimulate the development of nanocarriers allowing the delivery of TQ to the lungs. Once released in the respiratory system, the hydrophobic nature of the cargo facilitates its attachment to the lipophilic envelope of SARS-CoV-2.

\section{Introduction}

Black seed (Nigella sativa), also known as black cumin, is an annual flowering plant in the family Ranunculaceae (buttercup or crowfoot family) native to China, the Indian Subcontinent, Eastern Mediterranean, West Asia, and Northern Africa. It is a medicinal plant that is widely used in various traditional medicines, in particular in the regions mentioned above, but it is almost entirely unknown to Western medicine. The white and pale blue flowering plant has a rich historical background. ${ }^{1}$ Nigella sativa seeds were found in several ancient sites, including Tutankhamun's tomb. The Persian physician Avicenna, regarded as the father of early modern medicine, described the plant in his Canon of Medicine as a treatment for shortness of breath (dyspnea) ${ }^{2}$, which frequently accompanies pathological conditions such as asthma and pneumonia.

\section{Materials and Methods}

The mechanism of action which recommends TQ for the treatment of infections with the new coronavirus is derived from (I) coherent analysis of the complete therapeutic action spectrum of TQ including its antiviral, antibacterial, antiinflammatory and immunomodulatory effects, (II) analysis of the impact of variations in $\mathrm{pH}$ on the function of endosomes in general, and (III) comparison with the antiviral activity of CQ and HCQ, in particular, (IV) analysis of the diffusion of the TQ molecule in viscous media (cells and tissue) using a physicochemical model, as well as (V) consideration of the hydrophobic nature of TQ.

\section{Results and Discussion}

The clinically relevant and most studied active constituent of Nigella sativa is TQ. Of particular interest in the present context is the simultaneous prevalence of the antiviral, antibacterial, anti-inflammatory and immunomodulatory effect of TQ. ${ }^{1,3-7}$ In efforts to overcome infections from the new coronavirus, the individual actions of all four effects are crucial, and synergistically offer what at the moment no other drug is capable of offering. A comprehensive overview of the antiviral effect of TQ with emphasis on the coronavirus MHV-A59 (mouse hepatitis virus-A59) is provided by Ulasli et $a l{ }^{8}$ The group explored the antiviral effect of an extract containing TQ in vitro. Its administration before the infection of the cells with the coronavirus resulted in a decrease in the replication of the virus. Specific antiviral effects of TQ are presented at least in seven articles, including, but not limited to hepatitis $\mathrm{C}$ virus, ${ }^{9-11}$ the H9N2 avian influenza virus, ${ }^{12,13}$ cytomegalovirus, ${ }^{14}$, and the Epstein-Barr virus. ${ }^{15}$ Antibacterial properties of TQ in general, ${ }^{16,17}$ and against chlamydia trachomatis $\mathrm{D}$, staphylococcus aureus and listeria monocytogenes, in particular, are addressed in several articles. ${ }^{18-20}$ The anti-inflammatory and immunomodulatory effects of TQ are the topics of four further publications. ${ }^{21-25}$

Ohkuma and Poole ${ }^{26}$ reported a rapid and substantial increase in the intra-lysosomal $\mathrm{pH}$ upon exposure of live cells to CQ that was only partially reversed when CQ was removed from the perfusion fluid. This effect can be explained via trapping of $\mathrm{H}^{+}$ions by CQ. HCQ appears to be very similar to its analog CQ in its impact on cellular function. It is widely accepted that both CQ and HCQ accumulate in lysosomes and inhibit function. Al-Bari ${ }^{27}$ reported that the raise in intra-lysosomal $\mathrm{pH}$ increases the permeability and volume of the lysosomes. According to Racoma et al. ${ }^{28}$ treatment of cells with TQ or CQ for six hours induced lysosome membrane permeability in vitro. Unfortunately, the literature is meager on details of the permeabilization process. At least, an interesting analogy recommends itself.

Since endosomes (membrane-bound structures within a cell that control the transport of substances in and out of a cell) can maturate into lysosomes, ${ }^{29}$ it is natural to translate and 
apply the basic principles observed in lysosomes to the endosomes. Chiang et al. ${ }^{30}$ reported the inhibition of the human immunodeficiency virus serotype 1 (HIV-1) using HCQ that inhibits the posttranslational modification of glycoprotein 120 (gp120) in T cells and monocytes. The mechanism of inhibition of gp 120 production was presumed to consist of the ability of HCQ to increase endosomal $\mathrm{pH}$ and therefore alter the enzymes required for the production of gp120. To further clarify this action, the authors determined the effect of HCQ and its enantiomers on endosomal $\mathrm{pH}$. Pretreatment of cells with HCQ increased endosomal $\mathrm{pH}$ to levels similar to those seen with CQ, decreased gp120 production, and suppressed HIV-1 replication.

The transport of endocytosed viruses has been instructively depicted by Savarino et al., ${ }^{31}$ who also hypothesized about the suitability of HCQ against SARS. In a study from 2020 March 18, focusing on COVID-19, Liu et al. ${ }^{32}$ added a further piece of information to the $\mathrm{pH}$ puzzle by converting the illustration of Savarino et al. into a straightforward sentence: "Since acidification is crucial for endosome maturation and function, we surmise that endosome maturation might be blocked at intermediate stages of endocytosis, resulting in failure of further transport of virions to the ultimate releasing site." With this picture in mind, we turn our attention to TQ.

To our knowledge, there is a lack of information on the impact of TQ on the morphology of endosomes. To understand its blocking function in endosomes, it is essential that it also provides an increase in $\mathrm{pH}$, analog to the action of CQ and HCQ. How can TQ increase the $\mathrm{pH}$ in the endosome as CQ or HCQ do, although TQ has no nitrogen atoms capable of catching protons from the environment and thus cannot directly increase the $\mathrm{pH}$ ? To solve this problem, it suffices to remember that TQ can be reduced into the corresponding hydroquinone species, acting as an oxidizing agent, ${ }^{33,34}$ similar to reactive oxygen species (ROS), a process illustrated in Figure 1.
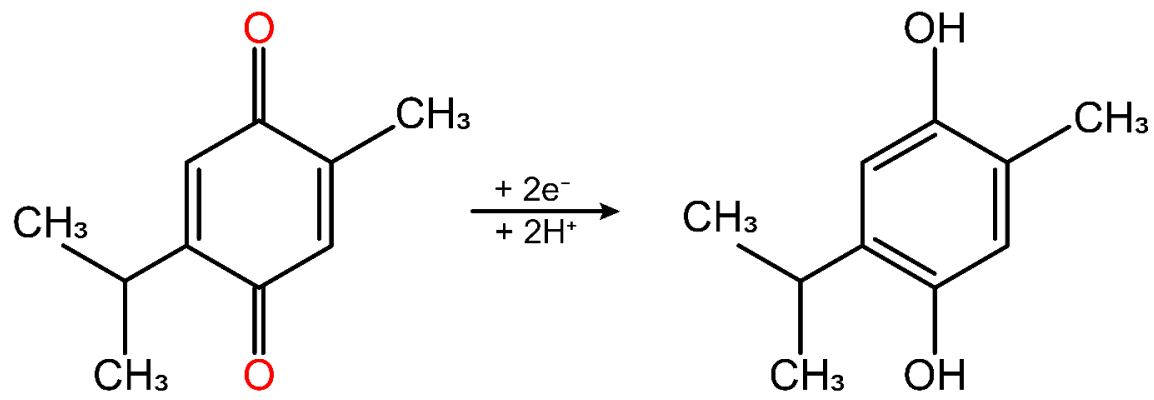

Figure 1. Structural formula of thymoquinone. Left: the molecule in its quinone form. Right: the molecule in the corresponding hydroquinone form. The Graphical Abstract was inspired by the shape of the molecule on the left as well as by its biological function, dictating the title of our paper.

Based on our hypothesis, it is reasonable to assume the following scheme: In a first step, TQ oxidizes some material inside the endosome, in analogy to the characteristic action of ROS. In this process, protons are removed from the proximal environment of TQ, actually leading in a second step to a $\mathrm{pH}$ increase. Besides this indirect mechanism of action, there exists a second modality by which TQ could neutralize a virus: The ROS-like character of the TQ molecule could be a direct route to oxidize a virus via surface contact, where surface contact is facilitated by the hydrophobic nature of the compound. ${ }^{33}$ It is likely that both mechanisms occur in nature.
The envisaged synergistic antiviral effect must be so powerful that one would be surprised if nature had made no use of it. From the perspective of its double antiviral potency, TQ appears to be superior to CQ and HCQ, which have only the capacity to alter $\mathrm{pH}$, and according to the FDA Safety Announcement [04-242020] have not been shown to be safe and effective for treating or preventing COVID-19. It is worth noting that CQ and HCQ are cationic amphiphilic drugs. ${ }^{35,36}$ This implies that during their journey through the body, the antimalarial drugs could be immobilized on surfaces in the predominantly hydrophilic environment, before reaching the target organs. The few molecules which eventually reached their destination 
could enter into the cells invaded by the virus due to their amphiphilic character.

In contrast, the hydrophobic nature of TQ is instrumental in preventing the drug from early immobilization during its transit to the target organs. Because of its hydrophobicity and smaller size relative to CQ and HCQ, TQ could more easily cross the plasma membrane of infected cells. En route to infected cells TQ can destroy SARS-CoV-2 before entering the cells, simply by binding to the lipophilic envelope of the virus, in agreement with the hydrophobic nature of the compound, and by oxidizing it. Thus, the antiviral effect of CQ and HCQ is virtually restricted to $\mathrm{pH}$ modulation in endosomes. Whereas drug delivery systems could be prepared for the hydrophobic TQ in a one-stage process, immobilization of the polar CQ in hydrophobic nanoparticles is less trivial. ${ }^{37}$ When considering antiviral effects of ROS, we refer to the work of Paiva and Bozza. ${ }^{38}$

In a recent molecular docking study, Bouchentouf and Missoum ${ }^{39}$ proposed the hypothesis that nigellidine and $\alpha$-hederin, two compounds present in Nigella sativa, may inhibit SARS-CoV-2. In our opinion, this hypothesis is unsatisfactory for two reasons: (I) The conclusions are based on the assumption that the strength of docking is causal for the antiviral activity of the compounds. Except for the molecular docking energies, no particular mechanism of inhibition is proposed. (II) Water molecules within the structures are not considered, although they are most important in biological systems. In addition, the authors do not discuss the error limits in their calculations. The data are presented with an unbelievable accuracy of $10^{-9}$, obviously a complete misinterpretation of the output data in their computing software. In addition, we must consider how fast a molecule can reach a target through a viscous medium. The diffusion rate is proportional to the molecule's diffusion coefficient, which is described by the Stokes-Einstein equation:

$$
\mathrm{D}=\frac{\mathrm{kT}}{6 \pi \eta \mathrm{r}}
$$

where $\mathrm{D}, \mathrm{k}, \mathrm{T}, \eta$, and $\mathrm{r}$ stand for the diffusion coefficient, Boltzmann constant, absolute temperature, viscosity of the medium, and radius of the molecule, respectively. Thus, the smaller the size of a molecule, the easier it can diffuse in a viscous medium.
Compared to TQ, the size of nigellidine and $\alpha$-hederin molecules is relatively large. Thus, the time for TQ to reach a pathogen attached to or incorporated into a cell is expected to be shorter than for nigellidine and $\alpha$-hederin. In other words, TQ should be a faster virus killer than nigellidine or $\alpha$-hederin. Likewise, the residence time of TQ in the body is expected to be superior to that of nigellidine and $\alpha$-hederin: In agreement with the relatively smaller size, TQ could penetrate deeper into tissue than the compounds nigellidine and $\alpha$-hederin. Furthermore, the smaller size of the TQ molecule safeguards its superficial attachment. Because of these biologically relevant advantages, TQ is an ideal candidate for nanoencapsulation. This means, the docking energy is not the sole criterion for the efficiency of an antiviral compound. While docking is a two-step statistical process, involving first the tracking of the pathogen and second the binding to a specific docking site, i.e., the product of the probability of two events, other, more general criteria appear to be more critical, for instance, a change in $\mathrm{pH}$ caused by the drugs and their capability to alter their immediate environment by oxidizing it. If TQ can contribute to an increase in endosomal $\mathrm{pH}$ and simultaneously attack the virus due to the two single oxygens in the TQ molecule, thereby simultaneously acting as both shield and sword, then its antiviral potency must be superior to that of nigellidine and $\alpha$-hederin as well as to that of CQ and HCQ. Moreover, a closer inspection of the chemical composition of the volatile fraction of black cumin oil reveals that the content of nigellidine and $\alpha$-hederin is about $1 \%$ of that of TQ. ${ }^{40}$ This ratio is in harmony with the statement that TQ is the major bioactive component of the oil. ${ }^{3}$

As a predictive tool, in silico calculations make only sense if complemented by additional data and/or a reasonable model allowing for the implementation of key parameters such as the effect of the molecular size, $\mathrm{pH}$, and structural aspects. However, in order to clinically exploit the full synergistic potential of TQ, it will be necessary to develop suitable biodegradable nanocarriers executing the delivery of the drug to the site of infection with SARS-CoV-2, for example, to the lungs. A substantial amount of work on the encapsulation of TQ has already been done, ${ }^{41}$ and the nanomedicines have already been successfully used to deliver TQ to 
various organs - except to the lungs. ${ }^{42-45}$ This justifies the expectation that our findings, supported by the literature provided, will help the nanomedicine community with expertise in the design of drug delivery systems to perform a quantum leap towards a strategy to protect cells from being infected by the novel coronavirus as well as to neutralize it. Innovative strategies for the delivery of a hydrophobic drug targeting the lungs are presented in a recent paper. ${ }^{46}$

\section{Anecdotal Case Report}

One of the authors of this paper (APS) became sick at the end of February 2020 upon return from a 10-day trip that included several hours stay inside a densely crowded international airport in East Europe, with some people already wearing protective masks. The first symptoms appeared nine days after returning home and included extreme weakness accompanied by excessive muscle pain with mild fever for two consecutive days. The fever increased gradually, but not over $38^{\circ} \mathrm{C}$, and was paralleled with a dry and unusually painful cough, which originated in a region deeper than what would be expected with bronchitis. Although the patient did not leave the house and did not expose himself to cold air and remained in bed, overnight, he developed a very painful frontal sinusitis. Painkillers (aspirin, ibuprofen, and vasograin) had virtually no effect. Further, the lung air volume was noticeably reduced, which manifested itself by the fact that the pressure was insufficient when trying to blow up the nose. Also, there was a temporary loss of smell perceived when incense was burned in the room. Except for the abovementioned pain killers taken because of a strong headache caused by the sinus- itis problem, only black cumin oil had been ingested by the patient with the following dosage: three times per day one tablespoon $(5 \mathrm{~mL})$ with a total of $120 \mathrm{~mL}$ used in eight days. To reduce the pain and the inflammation, the sinuses were irradiated with $670 \mathrm{~nm}$ LED light (Warp 10, Quantum Devices, Inc. USA). The use of red LED light (intensity $728 \mathrm{~W} / \mathrm{m}^{2}$ ) was indicated by its capacity to stimulate the production of adenosine triphosphate (ATP) in the mitochondria. ${ }^{47}$ Relevant for the current study is the further discovery of a strong antiviral effect of red laser light applied at an intensity of $20.000 \mathrm{~W} / \mathrm{m}^{2}$, demonstrated in a Herpes labialis model (CLINAM 12/2020). ${ }^{48}$

The symptoms disappeared seven days after they started. After a full recovery, the long-lasting chronic bronchitis disappeared as well. When it became evident that the virus has reached Europe before the outbreak of the infection causing the described symptoms, APS bought a $250 \mathrm{~mL}$ bottle of black cumin oil. Its purchase and use were motivated and encouraged by preliminary research for an upcoming book on paleopathology.

It would be imprudent to state that APS was infected for sure with SARS-CoV-2, although the symptoms described above coincide well with the lead symptoms in patients infected with SARS-CoV-2. Similarly, it would be impossible to claim that the good recovery was only due to the black cumin oil. This coincidence was, in fact, what stimulated us to do a comprehensive literature search on black cumin oil, which should be investigated further as one potential drug for treatment and prophylaxis of patients infected with SARS-CoV-2.

\section{Conclusion}

Given the extraordinary urgency of the matter, we hope that this study will be of help to the medical and scientific community to recognize the therapeutic and prophylactic potential of TQ (totally new to Western medicine) in general, and to put the nanomedicine community into the position to develop nanocarriers for its delivery to the lungs, in particular. The double antiviral mechanisms of action of TQ in concert with its antibacterial, anti-inflammatory, and immunomodulatory properties recommend TQ as a powerful instrument to combat the new coronavirus. All these properties are relevant when it comes to an infection with SARS-CoV-2. Our expectation is partially supported by the work of other groups. ${ }^{49}$ Apparently, TQ can be produced synthetically by the use of thymol, ${ }^{50}$ a substance with antimicrobial properties contained in toothpaste. In other words, large amounts of TQ could be produced, if necessary, in a very short period of time. Clinical applications of TQ with a focus on COVID-19 are at present being closely investigated. A precondition for a breakthrough is clarity about the mechanism by which TQ probably inhibits SARS-CoV-2. Translation of our model into clinical practice can be realized in two coordinated steps: In vitro validation of the antiviral mechanism proposed by us for TQ in laboratories with access to SARS-CoV-2, and design of suitable nanocarriers. 


\section{Acknowledgment}

APS is grateful to Prof. Noah Lotan (Technion, Haifa, Israel) for fruitful discussions. The authors thank Katlin E. Sommer (Bergische Universität Wuppertal, UWID, Germany) for designing the graphical content.

\section{Conflict of Interests}

The authors declare that there is no conflict of interest. For a signed statement, please contact the journal office: editor@precisionnanomedicine.com

\section{Author contributions}

Design of study: APS; Writing: APS with input from all authors. Methodology: APS and HDF; Substantial revision of the manuscript: KGN. All authors discussed the results and commented on the manuscript.

Quote this article as Sommer AP, Försterling HD, Naber KG, Thymoquinone: shield and sword against SARS-CoV-2, Precis. Nanomed. 2020;3(2):541-548, https://doi.org/10.33218/001c.12984

\section{References}

1. Rahmani AH, Aly SM. Nigella sativa and its active constituents thymoquinone shows pivotal role in the diseases prevention and treatment. Asian J Pharm Clin Res 2015;8:48-53.

2. Avicenna IS. Canon of Medicine. Kazi Publications, Inc., Chicago, Illinois, USA 1999.

3. Ahmad A, Husain A, Mujeeb M, Khan SA, Najmi AK, Siddique NA, et al. A review on therapeutic potential of Nigella sativa: A miracle herb. Asian Pac J Trop Biomed 2013;3:337-352.

4. Molla S, Azad AK, Al Hasib AA, Hossain MM, Ahammed S, Rana S, et al. A review on antiviral effects of Nigella sativa L. PharmacologyOnline, Newsletter 2019;2:47-53.

5. Yimer EM, Tuem KB, Karim A, Ur-Rehman N, Anwar F. Nigella sativa L. (black cumin): A promising natural remedy for wide range of illnesses. Evid Based Complement Alternat Med 2019;2019:1528635.

6. Forouzanfar F, Bazzaz BS, Hosseinzadeh H. Black cumin (Nigella sativa) and its constituent (thymoquinone): A review on antimicrobial effects. Iran J Basic Med Sci 2014;17:929-938.

7. Gholamnezhad Z, Havakhah S, Boskabady MH. Preclinical and clinical effects of Nigella sativa and its constituent, thymoquinone: A review. J Ethnopharmacol 2016;190:372-386.

8. Ulasli M, Gurses SA, Bayraktar R, Yumrutas O, Oztuzcu S, Igci M, et al. The effects of Nigella sativa (Ns), Anthemis hyalina (Ah) and Citrus sinensis (Cs) extracts on the replication of coronavirus and the expression of TRP genes family. Mol Biol Rep 2014;41:1703-1711.

9. Oyero OG, Toyama M, Mitsuhiro N, Onifade AA, Hidaka A, Okamoto M, et al. Selective inhibition of hepatitis C virus replication by Alpha-Zam, a Nigella sativa seed formulation. Afr J Tradit Complement Altern Med 2016;13:144-148.

10. Abdel-Moneim A, Morsy BM, Mahmoud AM, Abo-Seif MA, Zanaty MI. Beneficial therapeutic effects of Nigella sativa and/or Zingiber officinale in HCV patients in Egypt. EXCLI $J$ 2013;12:943-955.

11. Barakat EM, El Wakeel LM, Hagag RS. Effects of Nigella sativa on outcome of hepatitis C in Egypt. World J Gastroenterol 2013;19:2529-2536.

12. Umar S, Shah MAA, Munir MT, Yaqoob M, Fiaz M, Anjum S, et al. Synergistic effects of thymoquinone and curcumin on immune response and antiviral activity against avian influenza virus (H9N2) in turkeys. Poultry Sci 2016;95:1513-1520.

13. Eladl AH, Arafat N, El-Shafei RA, Farag VM, Saleh RM, Awadin WF. Comparative immune response and pathogenicity of the H9N2 avian influenza virus after administration of Immulant, based on Echinacea and Nigella sativa, in stressed chickens. Comp Immunol Microbiol Infect Dis 2019;65:165-175.

14. Salem ML, Hossain MS. Protective effect of black seed oil from Nigella sativa against murine cytomegalovirus infection. Int J Immunopharmacol 2000;22:729-740. 
15. Zihlif MA, Mahmoud IS, Ghanim MT, Zreikat MS, Alrabdi N, Imraish A, et al. Thymoquinone efficiently inhibits the survival of EBV-infected B cells and alters EBV gene expression. Integr Cancer Ther 2012;12:257-263.

16. Randhawa MA, Alenazy AK, Alrowaili MG, Basha J. An active principle of Nigella sativa L., thymoquinone, showing significant antimicrobial activity against anaerobic bacteria. $\mathrm{J}$ Intercult Ethnopharmacol 2016;6:97-101.

17. Bakal SN, Bereswill S, Heimesaat MM. Finding novel antibiotic substances from medicinal plants - Antimicrobial properties of Nigella sativa directed against multidrug-resistant bacteria. Eur J Microbiol Immunol (Bp) 2017;7:92-98.

18. Mosolygó T, Mouwakeh A, Hussein Ali M, Kincses A, Mohácsi-Farkas C, Kiskó G, et al. Bioactive compounds of Nigella sativa essential oil as antibacterial agents against Chlamydia trachomatis D. Microorganisms 2019;7. pii:E370.

19. Mouwakeh A, Kincses A, Nové M, Mosolygó T, Mohácsi-Farkas C, Kiskó G, et al. Nigella sativa essential oil and its bioactive compounds as resistance modifiers against Staphylococcus aureus. Phytother Res 2019;33:1010-1018.

20. Mouwakeh A, Telbisz Á, Spengler G, Mohácsi-Farkas C, Kiskó G. Antibacterial and resistance modifying activities of Nigella sativa essential oil and its active compounds against Listeria monocytogenes. In Vivo 2018;32:737-743.

21. Ikhsan M, Hiedayati N, Maeyama K, Nurwidya F. Nigella sativa as an anti-inflammatory agent in asthma. BMC Res Notes 2018;11:744.

22. Landa P, Marsik P, Havlik J, Kloucek P, Vanek T, Kokoska L. Evaluation of antimicrobial and anti-inflammatory activities of seed extracts from six Nigella species J Med Food 2009;12:408415.

23. Kheirouri S, Hadi V, Alizadeh M. Immunomodulatory effect of Nigella sativa oil on T lymphocytes in patients with rheumatoid arthritis. Immunol Invest 2016;45:271-283.

24. Salem ML. Immunomodulatory and therapeutic properties of the Nigella sativa L. seed. Int Immunopharmacol 2005;5:1749-1770.

25. Mahboubi M. Natural therapeutic approach of Nigella sativa (Black seed) fixed oil in management of Sinusitis. Integr Med Res 2018;7:27-32.

26. Ohkuma S, Poole B. Fluorescence probe measurement of the intralysosomal $\mathrm{pH}$ in living cells and the perturbation of $\mathrm{pH}$ by various agents. Proc Natl Acad Sci USA 1978;75:3327-3331.

27. Al-Bari MA. Chloroquine analogues in drug discovery: new directions of uses, mechanisms of actions and toxic manifestations from malaria to multifarious diseases J Antimicrob Chemother 2015;70:1608-1621.

28. Racoma IO, Meisen WH, Wang QE, Kaur B, Wani AA. Thymoquinone inhibits autophagy and induces cathepsin-mediated, caspase-independent cell death in glioblastoma cells. PLoS One 2013;8:e72882.

29. Hu YB, Dammer EB, Ren RJ, Wang G. The endosomal-lysosomal system: from acidification and cargo sorting to neurodegeneration. Transl Neurodegener 2015;4:18.

30. Chiang G, Sassaroli M, Louie M, Chen H, Stecher VJ, Sperber K. Inhibition of HIV-1 replication by hydroxychloroquine: Mechanism of action and comparison with zidovudine. Clin Ther 1996;18:1080-1092.

31. Savarino A, Boelaert JR, Cassone A, Majori G, Cauda R. Effects of chloroquine on viral infections: an old drug against today's diseases? Lancet Infect Dis 2003;3:722-727.

32. Liu J, Cao R, Xu M, Wang X, Zhang $\mathrm{H}, \mathrm{Hu} \mathrm{H}$, et al. Hydroxychloroquine, a less toxic derivative of chloroquine, is effective in inhibiting SARS-CoV-2 infection in vitro. Cell Discov 2020;6:16.

33. Asaduzzaman Khan M, Tania M, Fu S, Fu J. Thymoquinone, as an anticancer molecule: from basic research to clinical investigation. Oncotarget 2017;8:51907-51919.

34. Islam M, Sultana N, Alam Riaz T, Ferdous J, Guha B, Mohagon S, et al. Thymoquinone is knocking at the door of clinical trial. Int Arch Med 2016;9:1-25.

35. Ochsendorf FR. Use of antimalarials in dermatology. J Dtsch Dermatol Ges. 2010;8:829-944.

36. Salata $\mathrm{C}$, Calistri A, Parolin $\mathrm{C}$, Baritussio A, Palù G. Antiviral activity of cationic amphiphilic drugs. Expert Rev Anti Infect Ther 2017;15:483-492. 
37. Lima TLC, Carvalho Feitosa R, Santos-Silva E, Santos-Silva AM, Silva Siqueira EM, Machado PRL, et al. Improving encapsulation of hydrophilic chloroquine diphosphate into biodegradable nanoparticles: A promising approach against Herpes virus simplex-1 infection. Pharmaceutics 2018;10: 255.

38. Paiva CN, Bozza MT. Are reactive oxygen species always detrimental to pathogens? Antiox Redox Signal 2014;20:1000-1037.

39. Bouchentouf S, Missoum N. Identification of compounds from Nigella sativa as new potential inhibitors of 2019 novel coronavirus (Covid-19): Molecular docking study. doi.org/10.26434/chemrxiv.12055716.v1.

40. Amin B, Hosseinzadeh H. Black cumin (Nigella sativa) and its active constituent, thymoquinone: An overview on the analgesic and anti-inflammatory effects. Planta Med 2016;82:8-16.

41. Rathore C, Rathbone MJ, Chellappan DK, Tambuwala MM, Pinto TJA, Dureja H, et al. Nanocarriers: more than tour de force for thymoquinone. Expert Opin Drug Deliv 2020;17:479-494.

42. Fahmy HM, Fathy MM, Abd-Elbadia RA, Elshemey WM. Targeting of Thymoquinone-loaded mesoporous silica nanoparticles to different brain areas: In vivo study. Life Sci 2019;222:94-102.

43. Alam M, Najmi AK, Ahmad I, Ahmad FJ, Akhtar MJ, Imam SS, et al. Formulation and evaluation of nano lipid formulation containing CNS acting drug: molecular docking, in-vitro assessment and bioactivity detail in rats. Artif Cells Nanomed Biotechnol 2018;46(sup2):46-57.

44. Elmowafy M, Samy A, Raslan MA, Salama A, Said RA, Abdelaziz AE, et al. Enhancement of Bioavailability and Pharmacodynamic Effects of Thymoquinone Via Nanostructured Lipid Carrier (NLC) Formulation. AAPS PharmSciTech 2016;17:663-672.

45. Odeh F, Ismail SI, Abu-Dahab R, Mahmoud IS, Al Bawab A. Thymoquinone in liposomes: a study of loading efficiency and biological activity towards breast cancer. Drug Deliv 2012;19:371-377.

46. Ahmad N, Ahmad R, Almakhamel MZ, Ansari K, Amir M, Ahmad W, et al. A comparative pulmonary pharmacokinetic study of budesonide using polymeric nanoparticles targeted to the lungs in treatment of asthma. Artif Cells Nanomed Biotechnol. 2020;48:749-762.

47. Sommer AP. Mitochondrial cytochrome c oxidase is not the primary acceptor for near infrared light-it is mitochondrial bound water: the principles of low-level light therapy. Ann Transl Med 2019;7(Suppl 1):S13.

48. Sommer AP. Mitochondrial photo field-effect transistor: quantum tunneling \& photo sensitivity model explaining the brain death dogma challenge. Proceedings of the 12th European and Global CLINAM-Summit, 2020, Basel, Switzerland.

49. Ahmad A, Rehman MU, Alkharfy KM. An alternative approach to minimize the risk of coronavirus (Covid-19) and similar infections. Eur Rev Med Pharmacol Sci 2020;24:4030-4034.

50. Breyer S. Synthese, Funktionalisierung und Wirkoptimierung natürlicher Chinone. [dissertation], University of Bayreuth, Germany, 2010. 